\title{
Malignant fibrous histiocytoma of the gingiva
}

\author{
D Vijayalakshmi, Shabana Fathima, K Ramakrishnan, M Devi
}

Department of Oral \& Maxillofacial Pathology, Adhiparasakthi Dental College \& Hospital, Tamil Nadu, India

\section{Correspondence to Dr D Vijayalakshmi, vijigowdhaman@gmail.com}

\section{SUMMARY}

Malignant fibrous histiocytoma (MFH) is widely regarded as the commonest soft tissue sarcoma of adulthood which tends to occur in the deep soft tissues of the extremities and the retroperitoneum. Uncertain histogenesis and numerous subtypes make MFH a rather controversial entity. These tumours are relatively rare in the head and neck region accounting for only $1-3 \%$ of all cases of MFH. MFH exhibits a heterogenous histology of spindle cells in a characteristic storiform pattern with pleomorphic tumour cells and giant cells. A case is reported of an MFH of the gingiva in a 60-year-old woman who presented with a painful swelling originating from the left maxillary gingiva. The clinical, histopathological and immunohistochemical findings are discussed.

\section{BACKGROUND}

Malignant fibrous histiocytoma (MFH) was first described by O'Brien and Stout in 1964. It is the most common soft tissue sarcoma of late adult life with complex features and uncertain histogenesis. ${ }^{1}$ Its occurrence in the oral and maxillofacial region is however, extremely rare. Some of the reported sites include maxilla, mandible, buccal mucosa, temperomandibular fossa, tongue, gingiva, paranasal sinuses, salivary glands and retrorbital soft tissues. $^{2}$

$\mathrm{MFH}$ is a primitive often pleomorphic sarcoma consisting of partly fibroblast-like, partly histiocytelike cells. The tumour cells are derived from histiocytes capable of fibroblastic transformation. ${ }^{3} \mathrm{MFH}$ is an aggressive tumour, with a high potential of metastasis to other parts of the body. Repeated recurrences are common in patients with MFH before a confirmatory diagnosis is made. Furthermore, the prognosis may become poor due to distant metastasis. Therefore, correct diagnosis and initial treatment are extremely important for such sarcomas.

The purpose of this article is to present the clinical and histopathological characteristics of $\mathrm{MFH}$ occurring in the maxillary gingiva of a 60 -year-old woman and the need of immunohistochemical (ICH) analysis for a confirmatory diagnosis.

\section{CASE PRESENTATION}

A 60-year-old woman reported with complaint of a recurrent, painful, rapidly enlarging growth of the gums in the left upper back tooth region of 10 days duration. Her medical history was unremarkable. There was no significant contributing family history or history of trauma to the head and neck region. The patient noticed a swelling, 2 months back which was initially small and was painful. A month beforehand, the growth was excised from the mentioned site, in an independent clinic and was reported as a pyogenic granuloma. Later, the patient noticed a recurrent swelling at the same site that rapidly enlarged to the present size. It was associated with pain and difficulty in speech and mastication. There was no history of nasal obstructive symptoms, discharge or pain in relation to the maxillary sinus areas.

Intraoral examination revealed the presence of a solitary, sessile, irregular, pinkish red, well circumscribed, exophytic, nodular lesion which measured approximately $4 \times 3 \mathrm{c}$ in size (figure 1 ) The swelling extended from the distal aspect of left canine involving the attached gingiva and the alveolar mucosa buccally and palatally. The surface of the swelling was smooth with surface ulceration in a focal area. The inspectory findings were confirmed on palpation and the swelling was tender on palpation, firm in consistency, non-fluctuant, noncompressible and non-pulsatile. No mobility of the adjacent teeth could be demonstrated. No abnormalities were detected extraorally. The orthopantomograph did not reveal any relevant findings. Regional lymph nodes were not palpable. Based on the clinical findings and taking into account the rapidity of the growth provisional diagnosis of a sarcoma was made.

The intraoral mass was subjected to excisional biopsy. The cut surface was fleshy and yellowish white in appearance. Haematoxylin \& eosinstained sections of the tumour mass showed hypercellular areas composed of spindle cells and pleomorphic cells arranged in a classic, storiformpleomorphic pattern with scanty matrix. The fibroblast-like spindle cells were long and thin, as well as plump spindle cells with hyperchromatic, enlarged nuclei were seen arranged in a storiform pattern (figure 2). Numerous, irregular histiocytelike cells were scattered in the lesional tissue. The lesional cells were intermingled with a few multinucleated giant cells and chronic inflammatory cells like lymphocytes and plasma cells (figure 3). Mitotic figures were evident (figure 4). Focal

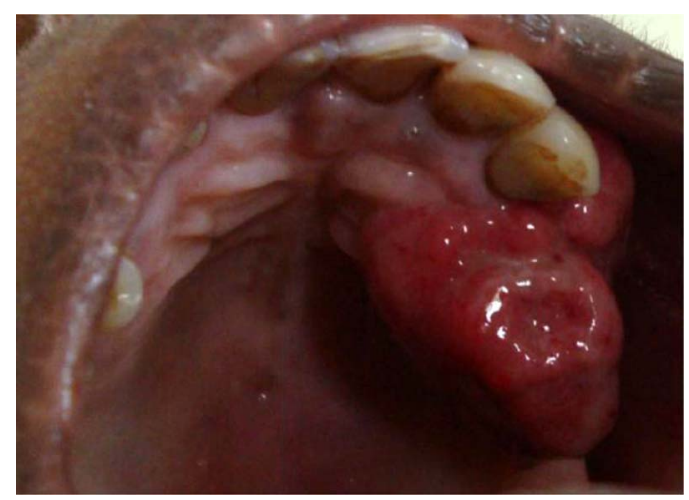

Figure 1 Intraoral photograph shows irregular, pinkish red mass. 


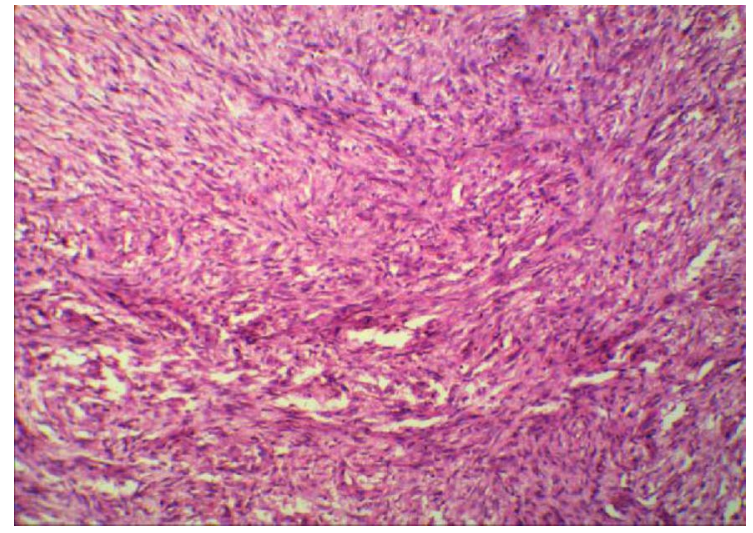

Figure 2 Storiform area showing spindled fibroblast-like pleomorphic cells arranged in short fascicles.

metaplastic bone formation, necrotic areas and a few areas showing myxoid stroma were seen. MFH is a diagnosis of exclusion. Careful histological evaluation was carried out to rule out any evidence of specific differentiation of rhabdomyoblasts, lipoblasts, smooth muscle cells and osteoblasts. MFH has no specific immunohistochemical marker. The lesional tissue was subjected to a panel of ICH markers to exclude haematolymphoid, melanocytic and epithelial differentiation. Immunohistochemistry played a vital role in distinguishing MFH from other pleomorphic sarcomas.

Based on the rapid growth of the lesion and histological features like hypercellularity, high mitotic activity, marked nuclear abnormalities and presence of necrotic areas, the tumour was graded as a high grade $\mathrm{MFH}$.

\section{INVESTIGATIONS}

Immunohistochemically, the tumour cells showed strong immunoreactivity for vimentin (figure 5) and strong cytoplasmic staining with CD68, a histiocyte marker (figure 6) although they showed negativity for cytokeratin, S-100 and smooth muscle actin. Based on the clinical aspects, histopathological and ICH findings, the final diagnosis of malignant fibrous histiocytomastoriform-pleomorphic type was made.

\section{DIFFERENTIAL DIAGNOSIS}

A differential diagnosis of fibrosarcoma, osteosarcoma, pleomorphic liposarcoma and leiomyosarcoma were considered.

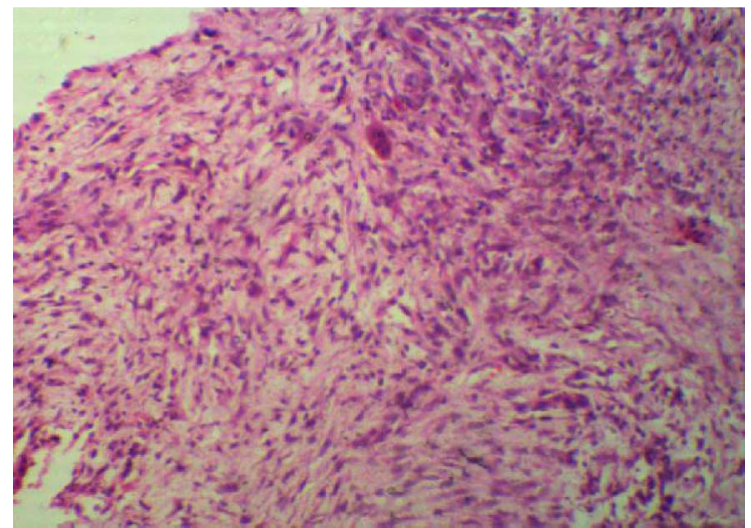

Figure 3 Multinucleated giant cells $(H \& E \times 40)$.

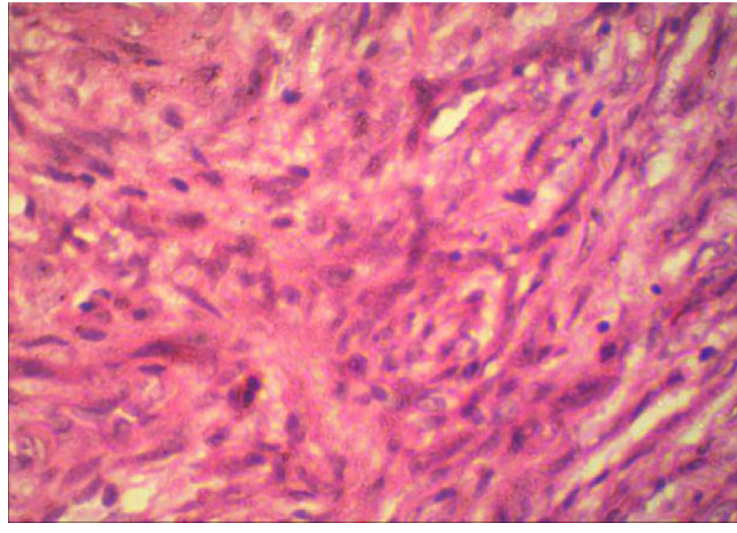

Figure 4 Pleomorphic area showing atypical mitotic figures.

\section{DISCUSSION}

Malignant fibrous histiocytoma (MFH) is a primitive, often pleomorphic sarcoma classified as a distinct histopathological entity since the $1960 \mathrm{~s} .{ }^{4}$ Nowadays, it is one of the most commonly diagnosed sarcomas of late adulthood, since all neoplasms previously regarded as sarcomas of uncertain origin are now included in this category. ${ }^{5}$ The malignant form of fibrous histiocytoma has attracted significant interest for several reasons: for its relative frequency, especially in the soft tissues, where it is the most common sarcoma in the adult: its ubiquity, since it presents in numerous locations due to its mesenchymal origin and its generally dim prognosis.

The exact histogenesis of this tumour remains controversial. The concept is derived from the questionable assumptions that histiocytes may act as facultative fibroblasts ${ }^{6}$ or that primitive mesenchymal elements may give rise to both fibroblasts and histiocytes. ${ }^{7}$ Histiocytes or tissue macrophages are derived from blood monocytes originating in the bone marrow. However, Groopman and Golde ${ }^{8}$ have presented histochemical evidence that some histiocytes may be activated forms of fibroblasts, thus lending support to the concept of fibrous histiocytic tumours. In addition to fibroblasts and histiocyte-like cells, there are other cellular components such as myxoid, foam, inflammatory and giant cells.

MFH involving the head and neck is rare. Though most of the cases represent tumours of soft tissue, it seems likely that $\mathrm{MFH}$ is a more ubiquitous tumour that may also arise from supporting structures of various organs and bone. Primary involvement of the oral soft tissues by MFH has been reported with

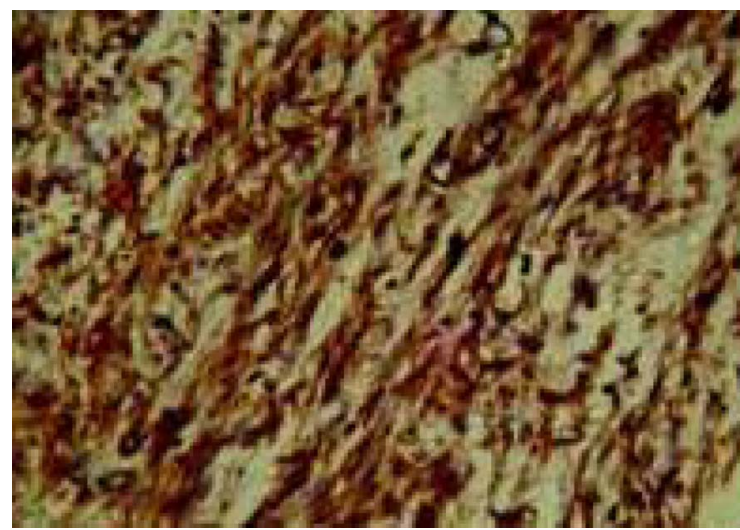

Figure 5 Strongly positive immunohistochemical reaction for vimentin. 


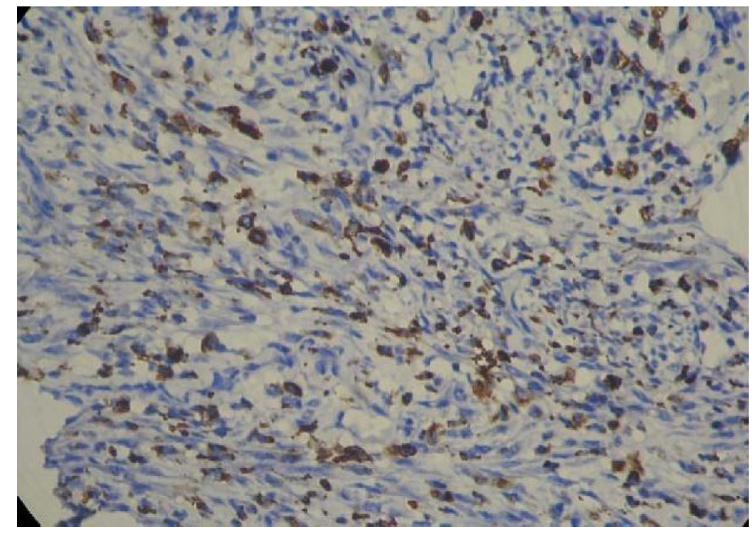

Figure 6 Tumour cells were stained with CD68 immunohistochemically.

only a few cases reported to occur in the gingiva. MFH tends to appear in the fifth and the sixth decades of life ${ }^{9}$ similar to our case. MFH has a male predominance $(61 \%) .{ }^{10}$ Signs and symptoms of MFH in head and neck region are similar among different cases which consist of a painful swelling that may be tender on palpation, similar to the present case. ${ }^{11}$

There are no well-known aetiological factors identified for malignant fibrous histiocytoma, but radiation exposure is suspected to play a causal role. Possible associations with Paget's disease or bone infarcts have also been described. ${ }^{12}$ In the present case, according to the patient's history there was no family history of any malignancy and systemic disease or any obvious inducing environmental or traumatic factor. The histological diagnosis of MFH of the head and neck can be challenging, especially with small biopsy specimens. Hence, multiple biopsies are sometimes required. In some instances, the diagnosis can be established with confidence only when the entire tumour has been excised and thoroughly examined. Diagnosis requires an adequate biopsy for electron microscopy and special stains. $^{13}$

$\mathrm{MFH}$ is a neoplasm with a fibroblastic nature and facultative histiocytic differentiation. Neville et $a l^{14}$ described this tumour with subtypes of histological presentation including storiform, pleomorphic, myxoid, giant cell, angiomatoid and inflammatory. The Storiform subtype is the most common variant composed of plump spindled cells with the fascicles appearing to radiate irregularly from focal zones. Areas with plump spindle cells containing enlarged, hyperchromatic and irregular nuclei are common. Presence of large, round cells resembling histiocytes often show some pleomorphism with round, central or eccentric, pale-staining nucleus and abundant cytoplasm. The pleomorphic pattern is characterised by plumper fibroblast-like cells with more pronounced nuclear atypia, greater numbers of rounded, histiocyte-like cells and pleomorphic giant cells.

The myxoid subtype is the next most common form consisting of hypocellular myxoid areas with abundant mucopolysaccharide production, in conjunction with cellular components that are analogous to those in the storiform-pleomorphic or xanthomatous subtypes. Inflammatory or xanthomatous MFH is characterised by the proliferation of histiocytes, xanthomatous cells and neutrophils, and it may be difficult to distinguish it from an inflammatory disorder. Angiomatoid MFH is characterised by sheets of histiocytes in association with blood-filled spaces. ${ }^{15}$ This variant has been reclassified within the fibrohistiocytic tumours of low malignant potential. ${ }^{16}$
Giant cell malignant fibrous histiocytoma involves multinucleated giant cells, histiocytes and fibroblasts. Often, osteoid accumulates at the periphery of the lesion. The angiomatous and myxoid subtypes have the best prognosis because of a lower propensity for systemic metastases. MFH may provide difficulty in the differential diagnosis of other sarcomas in the soft tissues. The differential diagnosis to be considered for $\mathrm{MFH}$ includes many entities like fibrosarcoma, pleomorphic rhabdomyosarcoma, pleomorphic liposarcoma and dedifferentiated sarcomas. ${ }^{12}$ Fibrosarcoma may contain areas with a storiform pattern but it typically lacks significant pleomorphism and has no histiocytic or bizarre multinucleated giant cells. Pleomorphic liposarcoma may contain large numbers of pleomorphic giant cells, and fat stains may not help to distinguish between it and MFH because the histiocytic cells of the latter may contain lipids and the pleomorphic cells of the former may not contain lipids. The diagnosis of liposarcoma is aided considerably by the finding of signet-ring lipoblasts, especially when differentiating myxoid liposarcoma from myxoid MFH.

Pleomorphic rhabdomyosarcoma can be separated from MFH by the presence of cross-striations or longitudinal myofibrils in lesional cells. In the absence of these it may not be possible to differentiate between these two malignancies without positive immunoreactivity with myogenic markers or the demonstration of rhabdomyoblasts by electron microscopy. Important clinical predictors of a poor outcome are male sex, advanced age, underlying systemic illness, large primary tumours, tumours arising from the bone and deep-seated tumours. In the head and neck region, the worst prognoses are for tumours arising from the maxillary sinus (60\% metastasis, $40 \%$ fatality), the mandible (40 and 30\%) and the larynx (22 and 44\%).

$\mathrm{MFH}$ of the oral region is usually treated by radical surgical resection. It is an aggressive tumour with a high potential of metastasis to other parts of the body. The rates of local recurrence and distant metastasis are $44 \%$ and $42 \%$, respectively. Five-year survival is poor, no more than $30 \%$.

\section{CONCLUSION}

Since MFH is rare in the oral cavity, misdiagnosis may not be unusual based on the initial clinical examination. As per our knowledge, only very few cases of $\mathrm{MFH}$ in the gingiva were found in the literature. The purpose of this case report was to add to the existing knowledge about this rare entity in the gingiva.

\section{Learning points}

- Malignant fibrous histiocytoma is the most common soft tissue sarcoma of late adult life with complex features and uncertain histogenesis.

- A correct diagnosis and initial treatment are extremely important for such sarcomas because repeated recurrences are common.

- The dentists must be familiar with such presentations and know the importance of immunohistochemical analysis.

Competing interests None.

Patient consent Obtained.

Provenance and peer review Not commissioned; externally peer reviewed. 


\section{REFERENCES}

1 Stout AP. Pathological aspects of soft part sarcomas. Ann NY Acad Sci 1964;114:1041-6.

2 Varma K, Mandal S, Jain S, et al. An ulceroproliferative growth in the gingiva: a cytological approach to the diagnosis. Cytopathology 2007;18:376-9.

3 O'Brien JE, Stout AP. Malignant fibrous xanthoma. Cancer 1964;17:1445-56.

4 Enzinger FM, Weiss SW. Soft tissue tumors. 3rd edn. Mosby, St Louis, 1995:83-112, 223-233.

5 Sturgis EM, Potter BO. Sarcomas of the head and neck region. Curr Opin Oncol 2003; 15:239-52.

6 Ozzello C, Stout AP, Murray MR. Cultural characteristics of malignant histiocytomas and fibrous xanthomas. Cancer 1963;16:331-4.

7 Fu YS, Gabbiani G, Kaye Gl, et al. Malignant soft tissue tumors of probable histiocytic origin (MFH): general considerations and electron microscopic and tissue culture studies. Cancer 1975;35:176-98.

8 Groopman JE, Golde OW. The histiocytic disorders: a patho-physiologic analysis. Ann Intern Med 1981;94:95-107.
9 Weiss SW, Enzinger FM. Malignant fibrous histiocytoma. An analysis of 200 cases. Cancer 1978;41:2250-60.

10 Blitzer A, Lawson W, Zak FG, et al. Clinical-pathological determinants in prognosis of fibrous histiocytomas of head and neck. Laryngoscope 1981;91:2053-70.

11 Fleury RN, Damante JH, Soares CT, et al. Malignant fibrous histiocytoma (undifferentiated high-grade pleomorphic sarcoma) occurring in tuberous sclerosis: case report. Oral Surg Oral Med Oral Pathol Oral Radiol Endod 2007;103:e54-9.

12 Barnes L, Kanbour A. Malignant fibrous histiocytoma of the head and neck. A report of 12 cases. Arch Otolaryngol Head Neck Surg 1988;114:1149-56.

13 Lin HS, Sidhu G, Wieczorek RL, et al. Malignant fibrous histiocytoma arising in the upper posterior triangle of the neck. Ear Nose Throat J 2001;80:560-2, 564, 566-7.

14 Neville, et al. Textbook of oral \& maxillofacial pathology. 2nd edn. Elsevier Publishers, 2002:481.

15 McMains C, Gourin CG. Pathology: Sarcomas of the head and neck. Emedicine 2007. Updated 26 March 2009.

16 Lagace R, Aurias A. Does malignant fibrous histiocytoma exist? Ann Pathol 2002;1:29-34.

Copyright 2012 BMJ Publishing Group. All rights reserved. For permission to reuse any of this content visit http://group.bmj.com/group/rights-licensing/permissions.

BMJ Case Report Fellows may re-use this article for personal use and teaching without any further permission.

Become a Fellow of BMJ Case Reports today and you can:

- Submit as many cases as you like

- Enjoy fast sympathetic peer review and rapid publication of accepted articles

- Access all the published articles

- Re-use any of the published material for personal use and teaching without further permission

For information on Institutional Fellowships contact consortiasales@bmjgroup.com

Visit casereports.bmj.com for more articles like this and to become a Fellow 